\title{
I.UMIRUNC
}

\section{PENETAPAN POTENSI SUMBER AIR PADA LAHAN KAMPUS 2 POLITEKNIK PERTANIAN NEGERI PAYAKUMBUH JORONG BATU KABAU NAGARI SITANANG}

\author{
Amrizal $^{* 1}$, Fazlimi ${ }^{1}$, dan Deswani Panggabean ${ }^{1}$ \\ ${ }^{1}$ Staf Pengajar Politeknik Pertanian Negeri Payakumbuh \\ Jl. Raya Negara Km. 7 Tanjung Pati, 26271, Payakumbuh \\ Korespondensi: amtalu@yahoo.co.id
}

$\begin{array}{ll}\text { Diterima } & : \text { 18 Juni } 2019 \\ \text { Disetujui } & : \text { 31 Agustus } 2019 \\ \text { Diterbitkan } & : \text { 31 Agustus } 2019\end{array}$

\begin{abstract}
ABSTRAK
Sumber air saat ini mengalami banyak penurunan, baik kuantitas maupun kualitas, karena ada banyak fungsi konversi lahan dari hutan ke pertanian, terutama di perbukitan dan daerah tangkapan. Agar pemanfaatan air dapat dilakukan secara berkelanjutan sambil tetap memperhatikan kemungkinan ketersediaan dan perubahan yang terjadi sebagai akibat dari pemanfaatannya, maka perlu perencanaan dasar untuk pengembangannya. Oleh karena itu, sebagai alat pendukung, panduan teknis diperlukan untuk mengevaluasi potensi air. Studi potensi mata air dilakukan oleh beberapa pendekatan, yaitu dengan lokasi geohidrology, debit musim semi, analisis tritium, analisis $18^{\circ}$, dan deuterium dan analisis kimia air yang menyediakan data dan informasi pelengkap (Purwitasari, 2006). Dalam penelitian ini kami melakukan lokasi geohidrologi dan pegas debit. Alat dan bahan yang digunakan adalah: Contour maps, GPS, Pharsall Flume. Sesuai dengan hasil penelitian, deskripsi dari diskusi dan tujuan dari sumber penelitian dapat digunakan sebagai berikut: 1. Di bidang pengambilan data diperoleh +145 titik koordinat, dimana titik ini akan digunakan dalam penentuan dari batas-batas dan konstruksi garis kontur yang dipetakan, 2. Sumber air potensial dalam format Universal Transverse Mercator (UTM) X 0696719, Y 9969672. Dalam bentuk data Geografis (00 16 '27, 32" dan 100046 '3.36' ') 3. Aliran perangkat flume pembuangan air adalah $0,36 \mathrm{~cm} 3 /$ detik.
\end{abstract}

Keywords: penetapan, potensi, sumber air

\begin{abstract}
Water sources at this time experience a lot of decline, both in quantity and quality, because there are many land conversions functions from forests to agriculture, especially in the hills and catchment areas. In order for water utilization to be carried out in a sustainable manner while still considering the potential availability and changes that occur as a result of its utilization, it is necessary to evaluate the potential of underground water as a basis for its planning and development. Therefore, as a supporting tool, technical guidelines are needed to evaluate the potential of water. The study of potential springs is carried out by several approaches, namely by location
\end{abstract}




\section{I.UMIRUNC}

geohydrology, spring discharge, tritium analysis, $18^{\circ}$ analysis, and deuterium and water chemistry analysis that provides complementary data and information (Purwitasari, 2006). In this study we conducted geohydrological locations and springs discharge. The tools and materials used are: Contour map, GPS, Parshall Flume. In accordance with the results of the study, a description of the discussion and the purpose of the research conducted in the allocation of water sources can be used as follows: 1 . In the field data retrieval is obtained +145 coordinate points, where this point will be used in the determination of boundaries and the construction of the mapped contour lines,2. The coordinates of potential water sources in the format of Universal Transverse Mercator (UTM) X 0696719, Y 9969672. In the form of Geographic data (00 16 '27.32' 'and 1000 46' $3.36^{\prime \prime}$ ')3. The flow of water discharge obtained by measuring using the parshall flume device is $0.36 \mathrm{~cm} 3 / \mathrm{sec}$.

Keywords: determination, potential, water sources

\section{PENDAHULUAN}

Air mempunyai peranan penting bagi semua kehidupan di dunia ini, tanpa air mustahil ada kehidupan di dunia ini. Oleh sebab itu air mempunyai peranan penting dalam menunjang semua aktifitas manusia. Dengan bertambahnya laju pertumbuhan penduduk dan berkembangnya semua aspek maka kebutuhan air pun juga semakin bertambah pula (Setiawan, dkk, 2012). Sumber air saat ini mengalami banyak penurunan, baik secara kuantitas maupun kualitas karena banyak terjadi alih fungsi lahan dari hutan menjadi pertanian, terutama didaerah perbukitan dan daerah tangkapanair (catchment area).

Pekerjaan karakterisasi sumber mata air ini sangat penting karena diperkirakan kekeringan cenderung terus meluas wilayah, intensitas dan durasinya, sehingga fenomena desertification harus mendapatkan perhatian khusus agar besaran (magnitude): luas dan intensitas dapat dideteksi lebih dini serta diminimalkan dampaknya. (Hendra, 2007). Tiga faktor yang menentukan besarnya debit mata air menurut Davis dan De Wist, (1966) adalah: Permeabilitas akuifer (tinggi muka air tanah), Luasan daerah resapan (recharge area) yang mengisi akuifer dan besarnya, Pengisian air tanah (groundwater recharge).

\section{METODE PENELITIAN}

\section{Tempat dan Waktu Penelitian}

Penelitian ini dilaksanakan pada lahan Politani 2 yang terletak di Jorong Batu Kabau Nagari Sitanang Kecamatan Lareh Sago Halaban, kabupaten Limapuluh Kota, 


\section{I.UMIRUNC}

provinsi Sumetera Barat.Penelitian ini dilakukan selama 5 bulan dari bulan Mei sampai Oktober 2016.

\section{Alat dan Bahan}

Adapun alat dan bahan yang dibutuhkan dalam penelitian ini adalah: GPS, kamera, komputer, parshall flume, software ArcGIS, alat tulis.

\section{Prosedur Pelaksanaan}

Langkah awal yang dilakukan dalam pengambilan data lapangan adalah dengan pembukaan jalan rintisan. Jalan rintisan dibuka dengan tujuan dapat mempermudah dalam pengambilan data koordinat dan dilanjutkan dengan pengolahan data di laboratorium.

\section{HASIL DAN PEMBAHASAN}

\section{Pengambilan Data Lapangan}

Hasil pengambilan data lapangan berupa data titik koordinat dilakukan setelah pembukaan jalan rintisan. Pengambilan titik koordinat dilapangan dilakukan sebanyak + 145 titik. Data titik koordinat yang diambil adalah dalam format data geografis. Data diolah supaya dapat menggambarkan kondisi lapangan. Data titik yang didapat dihubungkan untuk membuat batasan lahan dan data ketinggian tempat (elevasi) diolah untuk menggambarkan garis kontur dari lahan.

Koordinat potensi sumber air dalam format Universal Trasverse Mercator (UTM) X 0696719, Y 9969672, dan format dalam gegrafis adalah (00 16' 27,32'” dan 100046 ' 3,36'). Data ini didapatkan dari hasil survei lapangan dan pengolahan data di laboratorium.

Untuk pengukuran data aliran debit menggunakan Parshall Flume didapat ketinggian muka air adalah $\mathrm{H}=89 \mathrm{~mm}$. Data ini di dapat dari pengukuran kecepatan aliran air yang melalui kanal Parshall Flume di lapangan, dari hasil pengukuran di lapangan dilanjutkan pengolahan data di laboratorium. Data ini dibandingkan pada musim hujan dan musim kemarau, untuk melihat perbedaan debit sumber mata air.

\section{Pengolahan Data Lapangan}

Pengolahan data lapangan dilakukan untuk menetapkan dan mengambil keputusan dimana posisi titik yang berpotensi dijadikan sumber air, dimana sumber air ini dapat dijadikan sumber untuk pengairan sawah dan kebutuhan lainya. 


\section{I.UMIBUNG}

Hasil pengolahan data lapangan didapat:

a. Titik koordinat potensi sumber air Lahan Kampus 2 Politani format geografis (00 16'27,32'” dan 1000 46'3,36').

Untuk pengukuran data aliran debit menggunakan Parshall Flume didapat

$$
\begin{aligned}
& \mathrm{H}=89 \mathrm{~mm} \\
& \mathrm{Q}=\mathrm{C} . \text { Han } \\
& \mathrm{Q}=0,338.891,55=0,338 \times 1050,88=355,19 \mathrm{~mm} 3 / \mathrm{dtk}=0,36 \mathrm{~cm} 3 / \mathrm{dtk}
\end{aligned}
$$

b. Peta Kontur Lahan Kampus 2 Politani dapat dilihat pada Gambar 1.

c. Peta lokasi Potensi Sumber Air Lahan Kampus 2 Politani dapat dilihat pada Gambar 1. 


\section{I.UMBUNE}

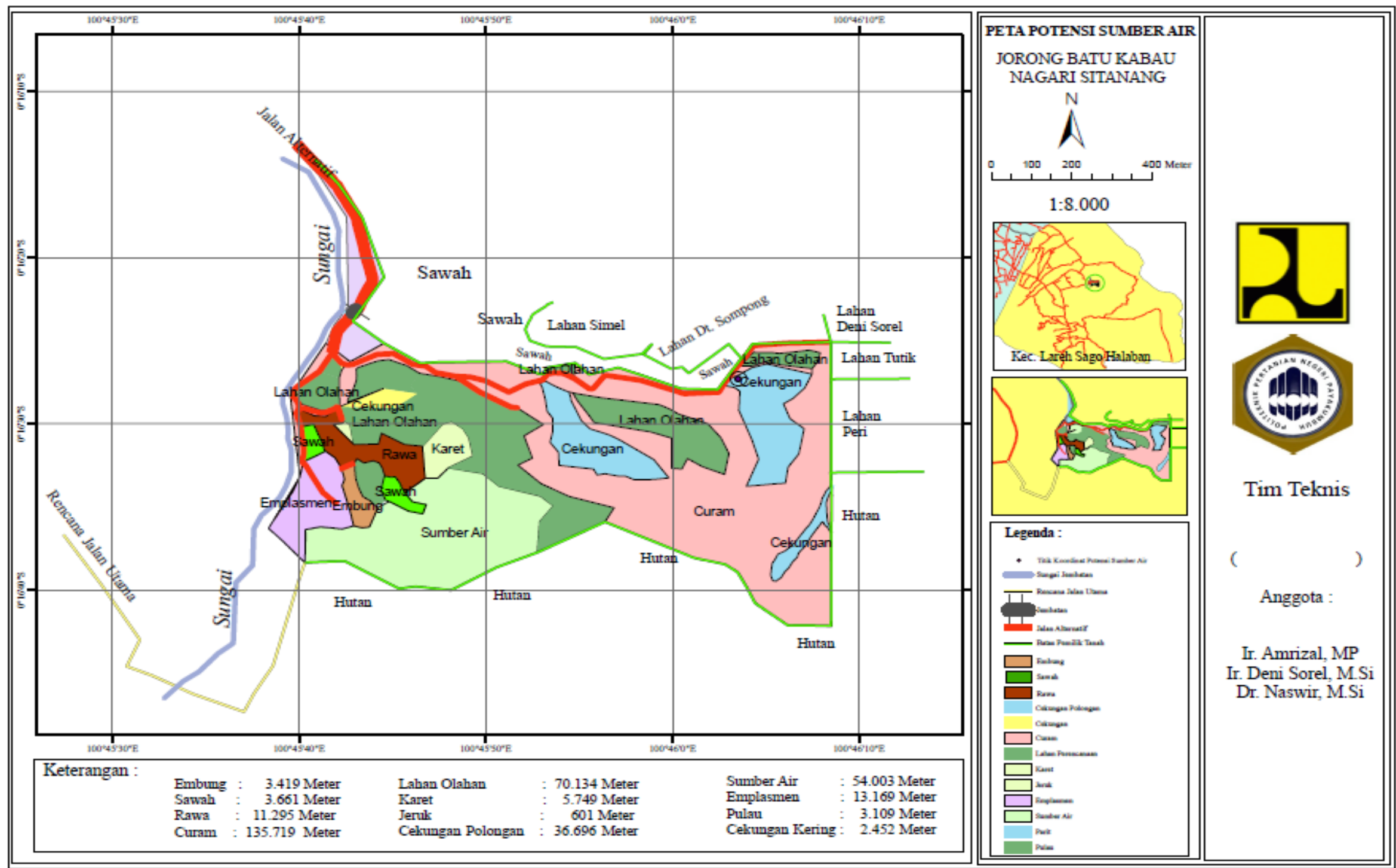




\section{I.UMIRUNC}

\section{KESIMPULAN DAN SARAN}

\section{Kesimpulan}

Sesuai dengan hasil penelitian dalam penempatan potensi sumber air maka dapat diambil beberapa kesimpulan sebagai berikut: dalam pengambilan data lapangan didapat \pm 145 titik koordinat, dimana titik ini yang akan dijadikan penentuan batas dan pembuatan garis kontur lahan yang dipetakan. Adapun koordinat potensi sumber air dalam format Universal Trasverse Mercator (UTM) X 0696719, Y 9969672. Format data Geografis (00 16' 27,32', dan 1000 46'3,36'). Aliran debit air yang didapat dengan pengukuran menggunakan alat Parshall Flume adalah $0,36 \mathrm{~cm} 3 / \mathrm{dtk}$.

\section{REFERENSI}

Agnis Purwitasari, Mardiana dan Oktia Woro. Studi Kelayakan Sumber Mata Air Kali Bajak Sebagai Pemenuhan Kebutuhan Air Bersih Warga di Wilayah Kelurahan Karanganyar Gunung Kecamatan Candisari Semarang Tahun 2006. Skripsi. Jurusan Ilmu Kesehatan Masyarakat, Fakultas Ilmu Keolahragaan, Universitas Negeri Semarang. 2006

Davis dan de Wist. Debit Mata Air, Graha Ilmu. Jakarta 1966.

Eka Wahyu Setiawan, A. Tunggul Sutan Haji, Bambang Suharto, "Identifikasi Potensi Sumber Air Permukaan Dengan Menggunakan Dem (digital elevation model) di Kabupaten Lembata Provinsi Nusa Tenggara Timur. Journal Sumber Daya Alam dan Lingkungan "identification of potential surface water sources using dem (digital elevation model) in the district of east nusa tenggara province" Fakultas Teknologi Pertanian, Universitas Brawijaya jl. Veteran, Malang 2012.

Hendra, Pemetaan Mata Air di Kabupaten Belu, NTT. Lipi Jakarta 2007. 